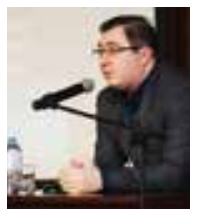

Руслан Эдуардович

КАЛИНИН,

аспирант кафедры судебной медицины и медицинского права

Московского государственного медико-стоматологического университета

имени А. И. Евдокимова

Минздрава России salem48@mail.ru

111399, Россия, г. Москва, Федеративный просп., Ә. 17

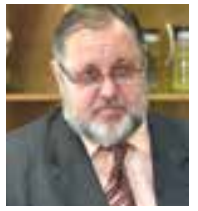

Евгений

Христофорович БАРИНОВ,

профрессор кафедры судебной медицины и медицинского

права

Московского государственного медико-стоматологического университета имени А. И. Евдокимова Минздрава Poccuu,

доктор медицинских наук, профрессор

ev.barinov@mail.ru

111399, Россия, г. Москва, Федеративный просп., д. 17

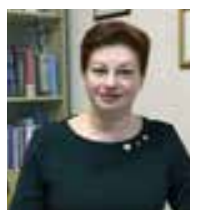

Ярослава

Владимировна

КОМИССАРОВА,

дочент кафедры криминалистики

Университета имени O.E. Кутафрина (МГЮА), кандидат юридических наук, доцент

a5143836@yandex.ru 125993, Россия, г. Москва, ул.

Садовая-Кудринская, д. 9

(C) Р. Э. Калинин, Е. Х. Баринов, Я. В. Комиссарова, 2021
ПОДМЕНА ПОНЯТИЙ И КОМПЕТЕНЦИЙ В ЗАКЛЮЧЕНИЯХ СУДЕБНО-МЕДИЦИНСКИХ ЭКСПЕРТОВ ПО «ВРАЧЕБНЫМ ДЕЛАМ» КАК НЕГАТИВНАЯ ТЕНДЕНЦИЯ ЭКСПЕРТНОЙ, СЛЕДСТВЕННОЙ И СУДЕБНОЙ ПРАКТИКИ 1

\begin{abstract}
Аннотация. Заключение комиссионной судебно-медицинской экспертизы играет ключевую роль в раскрытии признаков объективной стороны ятрогенных преступлений. При этом понятие дефекта оказания медицинской помощи в законодательстве отсутствует, а в теории и на практике не сложился единый подход к порядку установления причинно-следственной связи и ее характера (прямая или косвенная). Из-за отсутствия необходимого правового регулирования в экспертной и юридической практике сфрормировался ряд обычаев, не отвечающих требованиям формирования научно обоснованной частной криминалистической методики расследования преступлений и назначения уголовного судопроизводства.

В статье описаны наиболее распространенные ошибки, оказывающие негативное влияние на процесс расследования и разрешения так называемых «врачебных дел», из-за которых имеет место либо чрезмерный обвинительный, либо явно оправдательный уклон, что препятствует принятию справедливых и обоснованных процессуальных решений. Предложены пути совершенствования методики расследования ятрогенных преступлений, в том числе организации производства судебно-медицинских экспертиз по данной категории дел. Ключевые слова: медицинские услуги, расследование преступлений, ятрогенные преступления, судебно-медицинская экспертиза, компетенция, «врачебные дела», ненадлежащее оказание медицинской помощи, причинно-следственная связь.
\end{abstract}

DOI: 10.17803/2311-5998.2021.78.2.132-139

1 Исследование произведено при финансовой поддержке РФФИ в рамках научного проекта № 18-29-14084. 
postgraduate student of the Department

of forensic medicine and medical law

Moscow state medical and dental University of A. I. Evdokimov of the Ministry of health of Russia

salem48@mail.ru

111399, Russia, Moscow, Federativny prosp., 17

Ye. Kh. BARINOV,

Professor of the Department of forensic medicine and medical law Moscow state medical and dental University of A. I. Evdokimov of the Ministry of health of Russia,

Dr. Sci. (medical), Professor ev.barinov@mail.ru

111399, Russia, Moscow, Federativny prosp. , 17

Ya. V. KOMISSAROVA, Associated professor of Department of criminalistics of the Kutafin Moscow State Law University (MSAL), Cand. Sci. (Law), Associate Professor a5143836@yandex.ru 125993, Russia, Moscow, ul. Sadovaya-Kudrinskaya, 9

\title{
SUBSTITUTION OF CONCEPTS AND COMPETENCIES IN THE CONCLUSIONS OF FORENSIC EXPERTS ON «MEDICAL CASES» AS A NEGATIVE TREND IN EXPERT, INVESTIGATIVE AND JUDICIAL PRACTICE
}

\begin{abstract}
The conclusion of the Commission of forensic medical examination plays a key role in revealing the signs of the objective side of iatrogenic crimes. The notion of the defect of medical care in the legislation is absent, and in theory and in practice has not developed a unified approach to establish causality and its nature (direct or indirect). Due to the lack of necessary legal regulation in expert and legal practice, a number of customs have been formed that do not meet the requirements for the formation of a scientifically based private forensic methodology for investigating crimes and the purpose of criminal proceedings. The article describes the most common errors that have a negative impact on the process of investigation and resolution of socalled "medical cases", due to which there is either an excessive accusatory or clearly exculpatory bias, which prevents the adoption of fair and reasonable procedural decisions. Ways to improve the methods of investigation of iatrogenic crimes, including the organization of forensic medical examinations in this category of cases, are proposed.

Keywords: medical services, investigation of crimes, iatrogenic crimes, forensic medical examination, competence, medical cases, improper provision of medical care, cause-and-effect relationship.
\end{abstract}

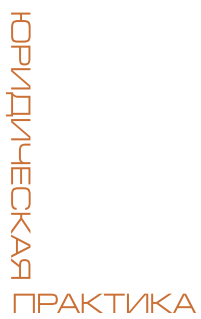




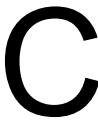

егодня, несмотря на все старания криминалистов, разрабатывающих современные методики допроса медицинских работников, проведения очных ставок, применения полиграфа и расширение процессуальных функций специалистов, в том числе за счет создания собственной судебно-медицинской службы (в структуре ФГКУ «Судебно-экспертный центр Следственного комитета Российской Федерации»), ход и исход «врачебных дел» по-прежнему определяются преимущественно выводами экспертов.

Бурный рост числа дел и, как следствие, экспертиз, связанных с профессиональными правонарушениями медицинских работников ${ }^{2}$, в том числе участившиеся случаи назначения повторных экспертиз, оголили ряд серьезных проблем, корни которых кроются как в пережитках давно устаревшей практики, так и в скудном правовом регулировании экспертной деятельности, оставляющем чересчур широкое поле для экспертного усмотрения на всех этапах проведения экспертизы - от определения перечня объектов и материалов, подлежащих исследованию, до ответа на поставленные перед экспертами вопросы.

При этом некоторые аспекты существующей практики характеризуются высокой опасностью неблагоприятных правовых последствий - от затягивания процесса до вынесения несправедливых судебных решений.

Ниже приведены результаты анализа ряда типичных ошибок, из-за которых экспертиза может в большей степени препятствовать установлению истины по делу, чем помогать в этом следствию и суду.

1. Подмена вопроса о причине и характере допущенных дефектов оказания медицинской помощи вопросом о персоналиях, их допустивших. Следователи постоянно ставят перед экспертами вопросы о том, кто из медиков допустил нарушения при оказании медицинской помощи, зачастую так: «Кто несет ответственность...». К сожалению, эксперты нередко идут на поводу у следствия и отвечают на такие вопросы, приводя фамилии медработников, указанные в медицинской документации или протоколах допросов.

Такой способ «идентификации» субъекта преступления нельзя признать допустимым. Отвечая на вопрос о личности медработника, по вине которого возникли дефекты, эксперты опираются на медицинскую документацию (о ее фальсификации сказано и написано так много, что дело однажды дошло до законопроекта о введении соответствующей статьи в УК РФ). Проверить достоверность сведений в медицинских картах эксперты не могут. Кроме того, указывая фамилию конкретного лица, чаще всего лечащего врача, эксперты тем самым делают вывод о том, что дефекты были допущены на этапе наблюдения, диагностики и лечения пациента, при этом суть самих дефектов сводится к действию либо бездействию указанного экспертами лица.

Остаются нераскрытыми организационные недостатки, работа административного персонала лечебного учреждения и органов управления здравоохранением, вопросы материально-технического оснащения и лекарственного обеспечения,

2 Стремление исследователей к решению данной проблемы столь велико, что ряд авторов отождествляют «врачебный процесс» и «ятрогенный процесс», тем самым приравнивая оказание медицинской помощи к преступлению. См., например: Мазур Е. С., Ахмедшин Р. Л., Александрова Я. Д. Криминалистическая характеристика ятрогенных преступлений // Вестник Томского государственного университета. 2020. № 451. С. 220-225. 


\begin{tabular}{|c|c|}
\hline 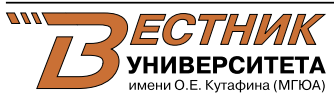 & $\begin{array}{l}\text { Калинин Р. Э., Баринов Е. Х., Комиссарова Я. В. } \\
\text { Подмена пОнятий и компетенЦий в заключениях судебно-медицинских } \\
\text { экспертов пО «Врачебным делам» Как негативная тенденция... }\end{array}$ \\
\hline
\end{tabular}

т.е. наличие реальной возможности оказать медицинскую помощь надлежащим образом. Эксперты должны отвечать на вопросы о том, на каком этапе оказания медицинской помощи были допущены дефекты, при проведении какого именно медицинского вмешательства это произошло, к какому профилю (врачебной специальности) относятся эти дефекты.

Персонификация юридической ответственности не должна осуществляться экспертным путем. Для установления конкретного лица, допустившего нарушения при исполнении профессиональных обязанностей, следователи должны изучить свидетельские показания, графики дежурств, табели учета рабочего времени и т.п. Специальные знания в области медицины для этого не нужны. При постановке вопроса о том, кто из медработников допустил дефекты оказания медицинской помощи, происходит подмена компетенций эксперта и следователя, т.е. незаконное и необоснованное делегирование полномочий следователя экспертам.

2. Вопрос о наличии и характере причинно-следственной связи между дефектами оказания медицинской помощи и неблагоприятным исходом зачастую подменяют вопросом о возможности благоприятного исхода при правильном оказании медицинской помощи. Признаком объективной стороны ятрогенного преступления с материальным составом является прямая причинно-следственная связь, которая должна быть установлена при определенных обстоятельствах и для конкретного пациента ${ }^{3}$.

Установление причинной связи по «врачебным делам» представляет собой известную проблему ${ }^{4}$, которую правоприменители регулярно пытаются обойти путем постановки теоретических и гипотетических вопросов о том, возможен ли был благоприятный исход при безупречном лечении. Однако эксперты и юристы должны отдавать себе отчет в том, что никакой методики исследования по такому вопросу не существует. Нельзя вернуться в прошлое, оказать пациенту надлежащую медицинскую помощь и узнать, каков будет исход. Эксперты могут дать только литературную справку о статистике летальности и других исходов при определенной патологии на различных стадиях, при разных сроках начала лечения, в зависимости от его методов и т.д.

Никакого научно-практического способа применить эти данные к конкретному больному в рамках экспертизы не существует. Если при болезнях, которые при адекватном лечении характеризуются очень низким процентом осложнений и смертей, иногда можно пренебречь такой погрешностью и условно перенести общие закономерности на исследуемый клинический случай, то при патологиях с высокой летальностью экспертам следует сосредоточиться на решении вопроса о наличии и характере причинной связи, а не пускаться в абстрактные рассуждения о статистике. В противном случае возникает риск неправосудных обвинений в причинении смерти или тяжкого вреда здоровью, основанных только на том факте, что эксперты посчитали теоретически возможным благоприятный исход.

3 См., например: Мащенских Н. В. Ненадлежащее исполнение своих профессиональных обязанностей как обязательный признак объективной стороны ятрогенного преступления // Синергия наук. 2019. № 42. С. 822.

4 См., например: Дмитриева О. А., Голубева А. В., Косинская Е. Д. Проблемы установления причинно-следственных связей при проведении судебно-медицинской экспертизы «ятрогенных преступлений» // Вестник судебной медицины. 2019. Т. 8. № 4. С. 56-61.

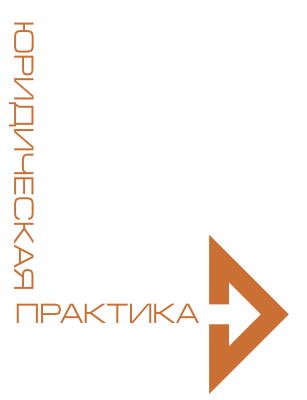


3. Подмена понятия ятрогенного осложнения понятием обоснованного медицинского риска. Любое медицинское вмешательство сопряжено с определенной степенью риска развития осложнений, вероятность возникновения которых предопределена методикой проведения данного вмешательства. Каждая операция, манипуляция или процедура характеризуется тем или иным процентом свойственных ей осложнений. Однако это вовсе не означает, что развитие типичного осложнения в каждом случае должно расцениваться как закономерный и непредотвратимый фринал.

4. Ссылки экспертов на общую частоту встречаемости осложнений без какоголибо анализа причин неблагоприятного исхода в конкретном случае являются одной из причин, по которым экспертов постоянно упрекают в «корпоративной солидарности» 5 . В рамках экспертизы требуется предметный анализ причин и условий возникновения ятрогенного происшествия, включая анализ показаний и противопоказаний к медицинскому вмешательству, методики и техники его выполнения, сроков развития осложнений и сроков их диагностики, а также других существенных факторов.

Заключение экспертов не должно сводиться к тому, что «такое случается». Необходимо выяснить, почему это случилось в конкретной клинической ситуации. Уклонение экспертов от объективного анализа обстоятельств ятрогенного происшествия приводит к уходу виновных лиц из числа медицинского персонала от ответственности, подрывает авторитет судебно-медицинской службы и способствует росту правового нигилизма среди медиков и пациентов.

Здесь уже можно говорить о подмене компетенции эксперта компетенцией специалиста, когда вместо исследования материалов конкретного дела эксперты опираются на медицинскую литературу, а в заключении вместо выводов излагают свои суждения по широкому кругу вопросов, не входящих в предмет доказывания по данному делу.

5. Подмена вывода о наличии дефектов оказания медицинской помощи выводом о наличии неблагоприятного исхода. Дефект оказания медицинской помощи - это нарушение обязательных правил ее оказания, утвержденных в установленном законом порядке и закрепленных в нормативных документах. Если эксперты пришли к выводу о том, что при оказании медицинской помощи были допущены дефекты, то они обязаны обосновать свой вывод ссылками на конкретные положения и требования, которые были нарушены медицинским персоналом. Вместо этого в заключениях экспертов нередко можно встретить выводы о наличии дефектов в диагностике и лечении, единственным основанием которых является сам факт развития осложнений медицинского вмешательства, заболевания или травмы. При этом эксперты не указывают никаких нарушений со стороны медиков, ссылаясь только на неблагоприятный исход, состоящий в прямой причинной связи с действиями медицинских работников.

Подобное толкование сути понятия «дефект оказания медицинской помощи» приводит к нарушению принципа недопустимости объективного вменения. Впоследствии медиков привлекают к уголовной ответственности за невиновное

5 Ерахмилевич В. В., Казанцев Д. А. Ятрогенные преступления и проблемы их расследования // Актуальные проблемы борьбы с преступлениями и иными правонарушениями. 2020. № 20-1. C. 43. 
причинение вреда, а иногда и просто за участие в оказании медицинской помощи, т.е. за надлежащее исполнение профессиональных обязанностей.

Особую опасность такая практика представляет в связи с ростом числа обвинений по ст. 238 УК РФ, которая все шире применяется к деяниям медицинских работников, чему в известной степени способствует правовая позиция Верховного Суда РФ. Недопущение подобных ситуаций, возникающих в том числе из-за ошибок в работе экспертов, в настоящее время - одна из задач правоохранительных органов ${ }^{6}$.

Сегодня одной из наиболее актуальных является проблема криминалистического и экспертного обеспечения расследования «врачебных ошибок» в сфрере акушерства и гинекологии, а также вспомогательных репродуктивных технологий ${ }^{7}$. Правонарушения в данной области деятельности встречаются все чаще и характеризуются тяжкими последствиями. Так, дело голландского врача Яна Карбаата, тайно оплодотворившего собственной спермой более 50 женщин $^{8}$, оказалось не единственным случаем подмены биологического материала. Недавно выяснилось, что другой голландский гинеколог из города Зволле с 1981 по 1993 г. использовал свою сперму для оплодотворения не менее 17 пациенток'. В России вспомогательные репродуктивные технологии также находятся в фокусе пристального внимания правоохранительных органов. В настоящее время ведется расследование и уже предъявлены обвинения в торговле людьми группе московских врачей в связи с оказанием услуг в сфрере суррогатного материнства ${ }^{10}$.

При этом нельзя не отметить, что и в сфере родовспоможения без применения технологий искусственной репродукции по-прежнему нередки фатальные исходы, обусловленные ненадлежащим оказанием медицинской помощи. В практике одного из авторов статьи (Р. Э. Калинина) такие случаи встречаются регулярно. Например, ошибки врача-анестезиолога при проведении операции кесарева сечения привели к развитию у роженицы вегетативного состояния, т.е. необратимого повреждения коры головного мозга. Во время операции не был своевременно установлен диагноз высокого спинального блока, в связи с чем не были проведены необходимые лечебные мероприятия, что привело к развитию тотального

6 Богомолова К. И., Касаев И. Х. К вопросу о совершенствовании деятельности правоохранительных органов по выявлению и предупреждению ятрогенных преступлений // Вестник Саратовской государственной юридической академии. 2020. № 1 (132). С. 178-184.

7 См., например: Замалеева С. В. Ятрогенные преступления в репродуктивной сфере по уголовному законодательству России и некоторых зарубежных стран. Хабаровск, 2019 ; Кручинина Н. В., Попов В. П. Выявление злоупотреблений и преступлений, связанных с фальсификацией в сфере вспомогательных репродуктивных технологий // Вестник Университета имени О.Е. Кутафина (МГЮА). 2019. № 3 (55). С. 95-100; Комиссарова Я. В. Использование полиграфра при проверке заявлений и сообщений о преступлениях, связанных с искусственной репродукцией человека // Криминалистическое обеспечение безопасности биотехнологий: материалы научно-практической конференции / под ред. Н. В. Кручининой, Я. В. Комиссаровой. М. : РГ-Пресс, 2020. С. 44-48.

8 URL: https://ria.ru/20190417/1552765502.html (дата обращения: 09.09.2020).

9 URL: https://lenta.ru/news/2020/10/07/tainyi_otec/ (дата обращения: 09.09.2020).

10 URL: https://www.interfax.ru/moscow/717562 (дата обращения: 09.09.2020). 
спинального блока ${ }^{11}$. Реанимационные мероприятия при этом провели несвоевременно и не в полном объеме, что повлекло тяжелое поражение головного мозга.

Врач-анестезиолог был обязан проявить особую настороженность и повышенное внимание к возможности развития именно такого осложнения спинальной анестезии, какое в итоге произошло. Роженицы относятся к группе риска по развитию тотального спинального блока за счет повышенного внутрибрюшного давления и диафрагмального типа дыхания. Ятрогенное осложнение эпидуральной анестезии в виде непреднамеренной пункции субарахноидального пространства дополнительно повысило риск развития высокого и тотального спинального блоков, что также должен был учесть анестезиолог. Однако, приняв решение о применении спинальной анестезии вместо первоначально запланированной эпидуральной, анестезиолог не проинформировал об этом акушеров-гинекологов, не дал им возможности принять меры по профилактике тотального спинального блока, например в виде придания пациентке особого положения на операционном столе (с приподнятым головным концом стола).

Следует отметить, что дефекты оказания медицинской помощи заключались не в самом факте развития осложнения, а в несвоевременном оказании медицинской помощи по поводу данного осложнения. Врач-анестезиолог не мог предотвратить такие осложнения, как непреднамеренная пункция субарахноидального пространства и высокий спинальный блок, и сами по себе эти осложнения не являлись дефектами оказания медицинской помощи. Однако анестезиолог был обязан предвидеть возможность развития осложнений, поскольку эта возможность была предопределена не только особенностями состояния больной (беременность), но и особенностями выполнения анестезии (непреднамеренная пункция субарахноидального пространства), о чем врач знал и отразил это в медицинской карте.

Предвидя возможность указанных осложнений, врач обязан быть готов к незамедлительному проведению реанимационных мероприятий. В данном случае несвоевременное проведение реанимационных мероприятий подтверждалось медицинской документацией. Согласно записям анестезиолога, остановка дыхания отмечена в 0:50, а интубация трахеи произведена в 0:55, т.е. только через пять минут ничем не обоснованной задержки. Именно за эти пять минут развилось тяжелое, непоправимое гипоксическое повреждение головного мозга (острое кислородное голодание), повлекшее в дальнейшем развитие стойкого вегетативного статуса. Время полной гибели коры головного мозга при механической асфриксии составляет 6-8 минут.

Таким образом, врачом-анестезиологом были нарушены клинические рекомендации «Анестезия при операции кесарева сечения» (раздел «Основные принципы проведения нейроаксиальной анестезии в акушерстве», С. 13, п. 8), а также клинические рекомендации «Нейроаксиальные методы обезболивания родов» (раздел 5 «Профилактика осложнений нейроаксиальной аналгезии в родах», С. 15 , п. 7) - не было обеспечено должное наблюдение. Кроме того, врач нарушил п. 8.1.4 практических рекомендаций «Регионарная аналгезия родов»: своевременно не выполнена интубация трахеи и не осуществлен перевод больной на ИВЛ. Все

11 Блокада местными анестетиками нервных корешков в шейном отделе спинного мозга, приводящая к резкой брадикардии, критическому снижению артериального давления и параличу дыхательных мышц, в том числе диафрагмы. 
перечисленные клинические рекомендации были утверждены Общероссийской общественной организацией «Федерация анестезиологов и реаниматологов» и действовали на момент оказания медицинской помощи.

Вышеуказанные обстоятельства установили в ходе двух комиссионных судебно-медицинских экспертиз. Наличие прямой причинно-следственной связи между дефектами оказания медицинской помощи и неблагоприятным исходом позволило квалифицировать его как причинение тяжкого вреда здоровью. Анестезиологу предъявили обвинение по ч. 2 ст. 118 УК РФ. Уголовное дело было прекращено в связи с истечением срока давности, а иск родственников к лечебному учреждению частично удовлетворен ${ }^{12}$.

\section{БИБЛИОГРАФИЯ}

1. Богомолова К. И., Касаев И. Х. К вопросу о совершенствовании деятельности правоохранительных органов по выявлению и предупреждению ятрогенных преступлений // Вестник Саратовской государственной юридической академии. - 2020. - № 1 (132). - С. 178-184.

2. Дмитриева О. А., Голубева А. В., Косинская Е. Д. Проблемы установления причинно-следственных связей при проведении судебно-медицинской экспертизы «ятрогенных преступлений» // Вестник судебной медицины. 2019. -T. 8. - № 4. - С. 56-61.

3. Ерахмилевич В. В., Казанцев Д. А. Ятрогенные преступления и проблемы их расследования // Актуальные проблемы борьбы с преступлениями и иными правонарушениями. - 2020. — № 20-1. - С. 42-43.

4. Замалеева С. В. Ятрогенные преступления в репродуктивной сфрере по уголовному законодательству России и некоторых зарубежных стран. - Хабаровск, 2019. - 76 с.

5. Комиссарова Я. В. Использование полиграфра при проверке заявлений и сообщений о преступлениях, связанных с искусственной репродукцией человека // Криминалистическое обеспечение безопасности биотехнологий : материалы научно-практической конференции / под ред. Н. В. Кручининой, Я.В.Комиссаровой. - М. : РГ-Пресс, 2020. - С. 44-48.

6. Кручинина Н. В., Попов В. П. Выявление злоупотреблений и преступлений, связанных с фальсификацией в сфере вспомогательных репродуктивных технологий // Вестник Университета имени О.Е. Кутафинна (МГЮА). — 2019. — № 3 (55). - С. 95-100.

7. Мазур Е. С., Ахмедшин Р. Л., Александрова Я. Д. Криминалистическая характеристика ятрогенных преступлений // Вестник Томского государственного университета. - 2020. — № 451. - С. 220-225.

8. Мащенских Н. В. Ненадлежащее исполнение своих профессиональных обязанностей как обязательный признак объективной стороны ятрогенного преступления // Синергия наук. — 2019. — № 42. — С. 820-827.

12 Решение Киевского районного суда г. Симферополя Республики Крым от 13.03.2020 по делу № 2-1/2020 (имеется в распоряжении авторов статьи).

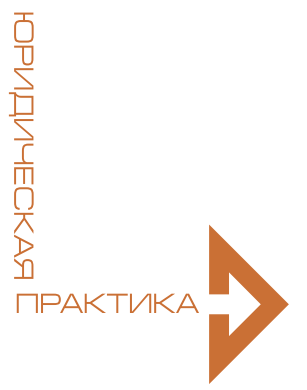

